\title{
NOTES FROM PRACTICE
}

\section{UIT DIE PRAKTYK}

\section{REFLECTIONS ON THE $15^{\text {TH }}$ WORLD AIDS CONFERENCE, BANGKOK, THAILAND: THE GREATEST SHOW ON EARTH?}

\section{Background and Context}

The $15^{\text {th }}$ World AIDS Conference took place in Bangkok, Thailand in keeping with the Conference Secretariat's decision a number off years ago to alternate conference sites between "western/northern" developed contexts and developing contexts. In addition, there was a strong sense that Thailand was an appropriate host country for the conference given its notable repose to HIV/AIDS and the resultant major reduction of prevalence statistics (from approximately 14,000 per year 6 years ago, to approximately 20,000 new reports per year at present $)^{4}$.

The theme of the conference was "Access for All", something of a "catch all" concept given the wide range of applications of the concept "access" in the field of HIV/AIDS (eg access to treatment, access to prevention, access to human rights, access to food etc etc). In many senses this "catch all" theme may have been the cause of the outrageously large number of accepted abstracts, with approximately 10,000 submitted, and, according to media reports in Thailand, approximately 8,000 accepted (either as presentations or posters). This, together with almost 20,000 participants ${ }^{5}$ resulted in as busy conference, but also one during which the quality of many submissions was questionable and the opportunity to maximise learning in concrete ways was somewhat reduced.

\section{Issues and Events that Characterised the Conference}

The conference was characterized by a number of issues/events. These are subjectively selected and reported here, however, the intention is that they serve to provide some insight into the dynamics at the event, and included:

- Considerable fanfare at opening and closing ceremonies: To some extent these events became occasions for opulence, spectacle, drama, faux par, and in some senses simple bad taste. The opening ceremony resembled a scene similar to that of a Hollywood event, with high tech lighting, smoke effects, dramatic music as speakers approached the stage/podium, and high-tech audio visual presentations to evoke emotions (generally, and in bad taste, of pity/sorry and similar). Sadly, but reflecting the reality of the society in which we live, the arrival of a Hollywood "star", Richard Gere promoted near hysteria, and stronger responses when compared with the welcome by the participants of prominent persons involved in the world of HIV/AIDS and world figures such as Kofi Annan. (To be fair, Mr Gere does have a foundation that supports HIV/AIDS work primarily in India and appears informed about HIV/AIDS issues). The ceremony's closing with "Miss Universe" leading a candle lighting ceremony took the event to even higher levels of what some may consider bad taste and, in some senses, demonstrated a

4 As reported by Thailand's Prime Minister, Thaksin Shinawatra at the conference opening ceremony.

5 XV International AIDS Conference, Friday 16 July 2004: "The Numbers". Figure excludes large number of Thai youth volunteers. 
basic lack of respect for those who were "being remembered", most having lived and died in contexts where they would not have even had a television to watch the likes of Miss Universe doing whatever it is that beauty pageant contest winners do to earn themselves the title. Nevertheless, for some the event was "touching" and may have served to highlight "the cause" in some way - if so, then this is good.

The closing ceremony was similar in nature, with the presence of Mr Nelson Mandela, Ms Sonia Gandhi and Ms Graca Machel being highlights. The presence of "angels", who flew in from "heaven" (i.e. the roof/ceiling area of the convention centre) suspended on cables and accompanied by falling glitter/tinsel, was something of a mysterious approach, and was generally lost to the crowd, most of whom had already departed to get to their busses and taxis before others (futile when all leave with the same idea) and make even more futile attempts to avoid the inevitable traffic congestion. Besides the angels, a dramatic production using children as its "stars" was staged that represented AIDS as an almost entirely medical issue, with children dressed as "patients" and indigent individuals limping and falling across the smoke covered stage, to eventually be "helped" by mini-nurses and mini-faith based characters, to be revived and all end up smiling and happy. This is not what AIDS is about, when approximately 14000 new infections are taking place globally every day and 38 million people are infected across the world, and certainly not what the World AIDS Conference, and indeed the $15^{\text {th }}$ version of it, should be about. However, the anxiety of the audience to depart to their transport and the possible good sense not to heckle (in too obvious a manner) children who had possibly not scripted the "spectacle" resulted in this relative off beat approach going largely un-noticed.

- Clear Absence of Leaders of State: Possibly one of the most noticeable "gaps" at the conference was the absence of significant "leaders of state". This was noted by many as problematic and Mary Robinson, Graca Machel and others in positions of power undertook to ensure that this lack of interest would not be repeated at future conferences (a task of considerable difficulty one would imagine). Perhaps the "shining star" was Dr Denzil Douglas, Prime Minster of a small Caribbean state, St Kitts and Nevis, who without much fanfare was a regular attendee at conference sessions and presented a paper at a supplementary session. The presence of Mr Yorwei Museveni, the President of Uganda, who addressed the opening ceremony was also noted as significant, and an example for leaders who were not present.

From a South African perspective the absence of President Mbeki was without surprise given his stance on HIV/AIDS, however the presence of the Minister of Health, Dr TshabalalaMsimang did little to enhance the image of the South African government, particularly when she engaged in hostile and somewhat misinformed interaction at the conference with the Treatment Action Campaign - predictably in relation to anti-retroviral issues. It is clear that no level of "spin-doctoring" will serve to facilitate and enhanced view of the South African government with regards to HIV/AIDS. Thankfully, honourary South African, Graca Machel, and the ultimate South African, Nelson Mandela worked their personal magic and redeemed, as far as it was humanly possible, the image of South Africa - although even they battle in light of the fact that South Africa holds the dubious honor of being home to the most people with HIV/AIDS in the world (and yet its official representatives still argue about ARVs in public!). 


\section{Reflection}

I have long questioned the real value of conferences of this nature, first of all in terms of size, which in turn relates, often, to the quality of presentations and interactions. The organizers should surely do some serious thinking about the evolution of the conference into something of an expensive $^{6}$ "traveling circus" that each time moves even further away from the reality of HIV/AIDS. This is not an original criticism or suggestion - it has been heard for many years.

Despite the issues raised above, the conference does have value in some senses. It serves as a reminder, even if abstractly, of how AIDS remains an issue that is split very much between north/south and east/west, sadly. More than a decade ago at similar conferences we would ask (across the geographical divides) - "are we talking about the same thing here?"

The conference also does provide people with opportunities to meet others involved in similar work and in this way, even, and possibly best at a personal level, to learn and engage with new ideas and approaches, or to reflect critically on "old" approaches. It also provides a platform for people to express concerns, to protest and to be heard (even if fleetingly). This then may in fact be the tension faced by the organizers; accepting large numbers of abstracts on the understanding that the acceptance of abstracts provides a platform, and often results in facilitating the means (funds) for people to attend such a forum.

At the risk of severe criticism, another point needs to be made. With all the talk about minority groups, the conference clearly forgot, at times, about heterosexual people. In its ongoing need to appease everybody (and yes, it is possible to do this), few speakers, for example, would even mention in their long list of people that needed to be addressed, the "average" heterosexual person. This is dangerous.

Also, there is a real need for issues of masculinity to be addressed; this is often forgotten when talking about "gender". We need to target men and boys, to liberate them from the stereotype and to do this urgently. The conference tended to forget this too.

Youth issues were popular at the conference, and rightly so. There is a change in youth demands; they don't want to be "consulted" anymore, they want REAL participation. This came up repeatedly. They want a say in things at a real level, and rightly so as they still see through clearer lenses than us adults and could have solutions un-clouded by adult cynicism. Young people also noted that they wanted the right to live - they made clear statements in presentations that they do not want to accept that they may be born into a terminal illness, they are beginning to demand the right to know that there is a "way out" for them.

From the "pure" sciences perspective, there was much talk about the development of microbicides - an exciting development in that there is real hope that current trials will bring about some positive results. Microbicides will provide women with more control, and in ways that make them possibly less at risk of abuse for taking control. Clear calls for maximum support of microbicide development came from a range of high profile speakers, including Nelson Mandela and Kofi Annan. Sadly, vaccine developments have still not produced results that suggest any significant changes in the near future - however, ongoing work in this field may, in the long-term produce the required results. 


\section{Closing comment}

I arrived at the conference expecting that it would be something of a jamboree/circus and it was, but it did serve to remind me of much and teach me some new ways of looking at issues especially, it at times made me feel optimistic again, something that happens seldom in our world these days.

My optimism related primarily to microbicide developments and the absolutely positive power of young people. I only wish the young people would stop saying that "we (the youth) are the future" - they are NOT the future, they are the present, here and now, and until they learn to say and accept this, people will always delay attention to their issues - and leave it for "the future", when indeed, it may be too late.

Note: This article is written in the author's personal capacity and does not reflect the opinions of his employer or any other party. 